\title{
RESTORASI KOMPLEKS KERAJAAN KAMPA BERDASARKAN KAJIAN SEJARAH DI KABUPATEN KAMPAR
}

\author{
Muhd. Arief Al Husaini*1) Wahyu Hidayat ${ }^{1}$ ) Abdul Latif Hasyim Datuok Bagindo²) \\ *) Corresponding author email : muhd.arief@lecturer.unri.ac.id \\ 1) Jurusan Arsitektur, Fakultas Teknik, Universitas Riau, Indonesia \\ 2) Museum AMM Kampar, Riau, Indonesia
}

\begin{tabular}{l} 
Article info \\
MODUL vol 21 no 2, issues period 2021 \\
\hline Doi $\quad: 10.14710 /$ mdl.21.2.2021.74-80 \\
Received $: 8$ maret 2021 \\
Revised $: 8$ juli 2021 \\
Accepted $: 16$ juli 2021
\end{tabular}

\section{Abstrak}

Banyaknya bukti dan keterangan yang mengatakan bahwa Kabupaten Kampar saat ini sudah eksis sejak abad 7 melalui peninggalan candi Muara Takus. Akar budaya dan adat sampai saat ini menjadi bagian penguat bahwa adanya kerajaan Kampa di kenegerian Kampa pada Abad 15. Ninik mamak 6 persukuan yang mampu menunjukkan keterangan baik secara lisan maupun benda seperti adanya stempel kerajaan, tanah hak milik kerajaan Kampa, sisa bangunan, dan pohon Asam Jawa yang berumum ratusan tahun. Namun eksistensi kerajaan berakhir pada tahun 1939 dikarenakan raja terakhir tidak memiliki keturunan, keluarga kerajaan kembali ke Malaysia, dan upaya penghadangan oleh penjajah Belanda. Sejak itu kompleks Kerajaan Kampa tidak terurus dan rusak termakan waktu hingga menyebabkan kerusakan dan kehilangan bangunan. Hingga saat ini yang tersisa adalah keping-keping bangunan dan benda-benda kerajaan lainnya. Untuk itu penelitian ini bertujuan untuk merestorasi kompleks Kerajaan Kampa berdasarkan fakta dan informasi sebenarnya. Sehingga hasil penelitian ini dapat digunakan oleh stakeholder seperti Pemerintah Kabupaten Kampar dan Ninik Mamak atau Penghulu adat/suku untuk merestorasi kompleks Kerajaan Kampa. Metode penelitian yang digunakan adalah deskriptif kualitatif dengan pendekatan sejarah. Pendekatan sejarah melalui tahapan pengumpulan dan pencarian keterangan atau bukti sejarah dari sumber-sumber yang terkonfirmasi seperti Ninik Mamak, Lukisan, Buku dan sebagainya. Selanjutnya dilakukan kritik terhadap sumber tersebut dengan melibatkan tim peneliti, pemerintah Kabupaten Kampar, dan Ninik Mamak. Terkahir melakukan tahap penulisan. Berdasarkan penelitian ini bahwa dihasilkan rancangan kompleks Kerajaan kampa dengan konsep budaya yang disebut Tali Tigo Sapilin Tigo Tungku Sajorangan, dimana didalam kawasan tersebut terdapat fungsi pemerintah melalui raja, persukuan melalui Ninik Mamak, dan agama melalui ulama (masjid). Penataan yang diterapkan berdasarkan zonasi yaitu zona inti untuk untuk fungsi kerajaan dan zona pendukung untuk Ninik mamak dan ulama.

Katakunci: Restorasi; Kerajaan Kampa; Kabupaten Kampar; Tali tigo Sapilin; Filosofi

\section{PENDAHULUAN}

Kabupaten Kampar seharusnya tidak dikenal sekedar sebagai sebuah wilayah administratif saja, namun jika melihat jauh kebelakang banyak sejarah yang harus ditelusuri. Wilayah ini sudah eksis sejak abad tujuh (7) sebagai bagian titik tolak hijrahnya Dapuntahyang yaitu pemimpin wilayah disekitar candi Muara Takus (Sriwijaya) di daerah Minanga Kampua atau Minanga Kanvar menuju daerah mukim baru dengan mendirikan kerajaan baru seperti Melayu Jambi, Melayu Palembang, dan sebagainya (Latif, 2018). Salah satu peninggalan besar adalah kompleks Candi Muara Takus yang diduga sebagai pusat kerajaan awal atau juga sering dikaitkan sebagai pusat pendidikan sekelas universitas. Selanjutnya pada abad ke 15 disinyalir sebagai awal berdirinya kerajaan islam di Kenegerian Kampa yang dikenal dengan nama Kerajaan Kampa.

Kerajaan Kampa ini berdasarkan tutur Ninik Mamak Kenegerian Kuok dan Kenegerian Kampa masih memiliki kekerabatan dengan Kerajaan Linduong Bulan 
Di Kenegerian Kuok, sebab raja pertama yang bernama raja Buyuong adalah anak kemenakan dari Kenegerian Kuok yang dihantarkan oleh utusan Kenegerian Kuok yaitu Datuok Bagindo Rajo, Datuok Penghulu Bosau, Datuok Bosau, Datuok Paduko Ulak, dan Datuok Paduko Majo (Latif, 2018). Pada tahun 1525 M Sultan Mahmud Syah Akhirul Zaman datang untuk menyelamatkan diri dan menyatakan bergabung dengan Kerajaan Kampa. Hal itu terjadi karena kerajaannya di Kesultanan Malaka direbut oleh Penjajah Portugis. Bertepatan adanya kekosongan raja di Kerajaan Kampa maka Sultan Mahmud Syah Akhirul Zaman diangkat sebagai raja baru di Kesultanan Kampa. Eksistensi Kesultanan Kampa berakhir pada tahun 1939 dengan raja terkahir adalah Sultan Adli Syah.

Bukti keberadaan Kerajaan Kampa masih bisa dijumpai sampai saat ini baik dalam bentuk tangible maupun intangible. Secara tangible atau suatu yang dapat dirasakan karakter secara visual dan material seperti adanya tanah bekas kompleks Kerajaan Kampa, Masjid Kubro sebagai masjid kerajaan, adanya kompleks pemakaman raja-raja, sisa-sisa dari bangunan istana, cap / stempel kerajaan, benda-benda peninggalan kerajaan Kampa. Secara intangible atau hal yang tidak terwujudkan seperti adanya perangkat adat, tambo adat dan cerita turun temurun, falsafah hidup, tradisi dan budaya Kerajaan Kampa.

Kekosongan pemimpin terjadi tahun 1939 saat raja Adli Syah mangkat. Sekaligus titik awal tidak terpeliharanya kompleks Kerajaan Kampa sehingga menimbulkan kerusakan bangunan. Beberapa sisa dari kompleks Kerajaan Kampa seperti Masjid Kubro, pohon Asam Jawa, dan tanah kompleks kerajaan itu sendiri. Kerusakan bangunan tersebut menimbulkan kehilangan khazanah arsitektur seperti langgam arsitektur, zonasi, dan kerancuan pola pergerakan dalam kawasan. Sehingga perlu adanya kajian kompleks Kerajaan Kampa agar dapat dikembalikan seperti semula sehingga menjembatani masa lalu, masa sekarang, dan masa akan datang.

Berdasarkan permasalahan tersebut maka perlu adanya penelitian mengenai restorasi kompleks Kerajaan Kampa berdasarkan fakta-fakta sejarah. Penelitian ini bertujuan untuk menemukan kembali kompleks Kerajaan Kampa seperti semula melalui pendekatan restorasi. Restorasi yang dilakukan pada aspek bangunan, filosofi, zonasi, perletakan bangunan, dan pola pergerakan kawasan.

\section{METODOLOGI PENELITIAN}

Berdasarkan latar belakang dan tujuan yang ingin dicapai maka penelitian ini menggunakan metode deskriptif kualitatif. Penelitian deskriptif kualitatif dinilai tepat untuk mencari nilai, persepsi masyarakat, dan juga proses perubahan yang sedang berlangsung
(Groat and Wang, 2002). Pendekatan penelitian yang dilakukan adalah pendekatan sejarah atau Heuristic yang melalui tahapan pencarian bahan sumber keterangan atau bukti, penilaian atau pengujian (kritik) terhadap bahan sumber sejarah, dan tahap penulisan yang bersifat formal (Wasino dan Endah, 2018). Sumber sejarah yang digunakan yaitu buku berjudul Sejarah Singkat Negeri Kampa dan Berdirinya Kerajaan Kampa-Riau yang ditulis Latif Hasyim Datuok Bagindo tahun 2018, wawancara dengan Datuok atau pemimpin adat wilayah Kampa, dan lukisan.

Wawancara dapat dilihat pada link berikut https://www.youtube.com/watch?v=wh3pfLoSLDM

Judul video Datuok Majo Bosau (Besar) Kenegerian Kampa. Ninik Mamak atau Penghulu Adat di Kenegerian Kampa yang dipanggil dengan Datuok (Dt / Datuk) :

1. Dt. Samsiwir sebagai Datuok Tumenggung Persukuan Domo (Pucuk Adat Kenegerian Kampa),

2. Dt. Afandi Muhammad Nur sebagai Datuok Majo Besar Persukuan Pitopang,

3. Dt. Afrizal sebagai Datuok Samad Dirajo Persukuan Bendang,

4. Dt. Fauzi sebagai Datuok Marajo Persukuan Kampai,

5. Dt. Bahar sebagai Datuok Besar Persukuan Piliang,

6. Dt. Auzar sebagai Datuok Tiawan Persukuan Melayu,

7. Dt. Safrizal sebagai Datuok Paduko Tuan Persukuan Melayu,

8. Dt. Mahyudin sebagai Datuok Bijoanso Persukuan Domo,

9. Serta dilengkapi oleh Dt. Abdul Latif Hasyim sebagai Datuok Bagindo Persukuan Bendang Kenegerian Kuok.

Salah satu sumber penting lainnya adalah lukisan istana Kerajaan Kampa yang di lukis oleh Abdul Latif Hasyim Dt. Bagindo melalui penelitiannya dengan mewawancarai Datuok Samad Dirajo tahun 2000 sebagai saksi yang melihat bangunan istana. Lukisan ini dikirm ke Kerajaan Malaka untuk dipamerkan/validasi. Kerajaan Kampa memiliki hubungan kekerabatan dengan Malaka (Malaysia) yang ditandai keturunan Kerjaan Malaka yang diangkat sebagai raja di Kerajaan Kampa (Latif, 2018). Pemenuhan kebutuhan sumber penelitian maka lukisan dibawa kembali ke Kenegerian Kampa oleh Abdul Latif Hasyim Dt. Bagindo pada tahun 2018. Selanjutnya informasi disajikan dalam bentuk gambar 2 dimensi dan 3 dimensi. Gambar tersebut dikritisi secara menyeluruh oleh Ninik Mamak agar mendapatkan ketepatan restorasi rancangan kawasan Istana Kampa. 


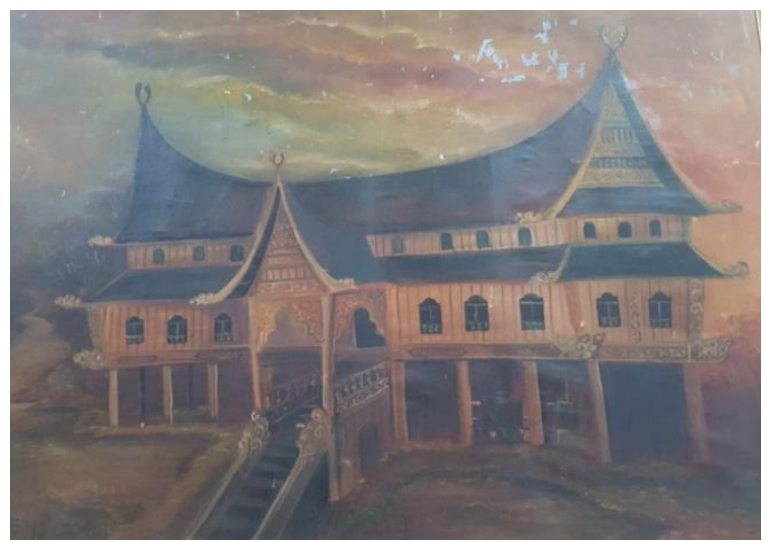

Gambar 1. Lukisan Istana Kerajaan Kampa Sebagai Sumber Penelitian (Latif Datuok Bagindo, 2000)

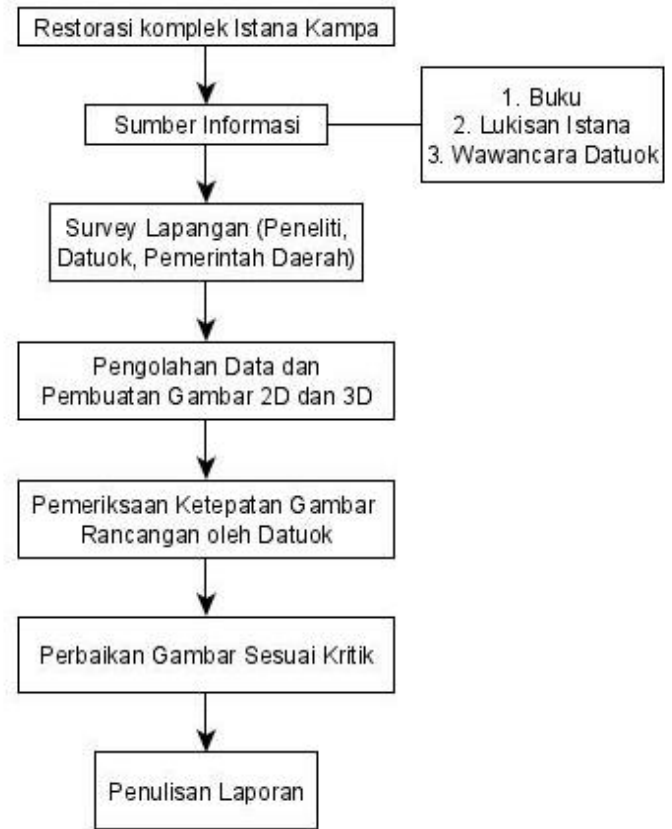

Gambar 2. Skema Penelitian Restorasi kompleks Kerajaan Kampa

\section{KAJIAN TEORI}

Undang-undang nomor 11 tahun 2010 tentang cagar budaya mengatakan bahwa cagar budaya adalah warisan budaya bersifat kebendaan berupa benda cagar budaya, bangunan cagar budaya, struktur cagar budaya, situs cagar budaya, dan kawasan cagar budaya di darat dan/atau di air yang perlu dilestarikan keberadaannya karena memiliki nilai penting bagi sejarah, ilmu pengetahuan, pendidikan, agama, dan/atau kebudayaan melalui proses penetapan. Selanjutnya dikatakan warisan budaya dapat berwujud tangible culture dimana warisan budaya berbentuk fisik seperti bangunan, monumen, buku, patung, dan artefak. Selain itu juga dapat berwujud intangible culture berbentuk non-fisik seperti budaya, cerita rakyat, tradisi, adat, bahasa, pengetahuan, warisan budaya berbentuk alami.

Sedangkan menurut Burra Charter (1992) bangunan cagar budaya adalah kelompok bangunan bersejarah dan lingkungannya, yang memiliki nilai sejarah, ilmu pengetahuan, dan nilai sosial budaya masa kini maupun masa lalu. Kriteria bangunan cagar budaya yang termuat dalam UU no 11 tahun 2010 harus berusia 50 (lama puluh) tahun atau lebih, mewakili masa gaya paling singkat 50 (lima puluh) tahun, memiliki arti khusus sejarah, ilmu pengetahuan, pendidikan, agama, dan/atau kebudayaan, dan memiliki nilai budaya bagi penguatan kepribadian bangsa.

Salah satu tujuan konservasi adalah upaya pengelolaan sumber daya budaya. Etika dalam konservasi yaitu menguasai karakter bangunan, respek dan hati-hati, menjaga dan memelihara, intervensi minimal, selalu terkait dengan sejarah, menguasai pengetahuan tentang bahan bangunan dan teknik pengolahannnya, dan selalu mendokumentasikan sebelum, selama, dan sesudah konservasi (Bernard Feilden, 2009).

Selanjutnya dikatakan konservasi merupakan rangkaian suatu proses memahami dan menjaga dengan melakukan pemeliharaan, perbaikan, pengembalian, dan adaptasi terhadap benda-benda aset sejarah untuk memelihara kepentingan kebudayaan dengan memperhatikan beberapa pendekatan nilai yaitu nilai umur dan kelangkaan, nilai arsitektur, nilai artistik, nilai kebudayaan, nilai asosiatif, nilai ekonomi, nilai pendidikan, nilai emosi, nilai sejarah, nilai kekhasan daerah, nilai masyarakat, nilai agama, nilai sosial, nilai simbolik, nilai teknik, nilai sains, penelitian dan pengetahuan, dan tampilan suatu kota (Aylin Orbasli, 2008).

Kegiatan dalam konservasi diantaranya preservasi, restorasi, rehabilitasi, rekonstrusi, konsolidasi, revitaliasi, dan demolisi. Melihat isu dan fakta permasalahan pada objek penelitian yang menunjukkan adanya kemerosotan kualitas lingkungan, perubahan penataan fungsi kawasan, serta rusaknya objek bangunan. Permasalahan tersebut menunjukkan pada kawasan penelitian perlu pengembalian kebentuk semula, yaitu kegiatan restorasi.

Kegiatan mengembalikan bentuk fisik suatu tempat kepada kondisi sebelumnya dengan menghilangkan tambahan-tambahan dengan merakit kembali komponen eksisting menggunakan material baru disebut dengan restorasi konteks luas. Sedangkan dalam konteks terbatas merupakan kegiatan pemugaran untuk mengembalikan bangunan dan lingkungan cagar budaya semirip mungkin ke bentuk asalnya berdasarkan data pendukung tentang bentuk arsitektur dan struktur pada keadaan asal tersebut dan agar persyaratan teknis bangunan terpenuhi (Ref.UNESCO.PP. 36/2005). 
Pada kawasan atau lingkungan objek dan lingkup restorasi digolongkan dalam beberapa luasan sebagai berikut (Attoe, 1978) :

- Satuan Areal, yaitu berwujud sub wilayah;

- Satuan Pandang atau View, yaitu berupa aspek visual yang memberikan bayangan metal (image) antara lain, path, edge, node, district, dan landmark; dan

- Satuan Fisik, yaitu berwujud bangunan, sederetan bangunan, bahkan unsur bangunan seperti struktur, ornamen dan lainnya.

Restorasi lingkungan pada daerah yang telah ditentukan sebagai lingkungan bersejarah dapat diberlakukan batasan-batasan tambahan secara khusus berkaitan dengan penggunaan bangunan dan konstruksi baru yang diijinkan. Penguatan citra kawasan dengan kehadiran suatu obyek atau karya akan mempengaruhi kawasan-kawasan sekitarnya dan bermakna untuk meningkatkan mutu dan citra lingkungannya (Attoe, 1978)

Berdasarakan lingkup objek pelestarian tersebut yang termasuk dalam bidang kajian arsitektur adalah pelestarian baik dalam lingkup areal maupun fisik yang berwujud bangunan atau kawasan bangunan yang didalamnya juga membahas tentang unsur pembentuk bangunan seperti, fasade, ornamen, struktur dan unsur lainnya yang memiliki nilai sejarah dan nilai estetika yang tinggi. perubahan-perubahan dapat dilakukan sampai batas-batas tertentu, agar bangunan dapat beradaptasi terhadap lingkungan atau kondisi sekarang atau akan datang. Proses mengembalikan obyek agar berfungsi kembali dengan melestarikan bagian-bagian dan wujud-wujud yang menonjol (penting) dinilai dari aspek sejarah, arsitektur dan budaya (Attoe, 1978).

\section{HASIL DAN PEMBAHASAN \\ Karakteritik Keadaan Terkini Kompleks}

Lokasi kompleks Kerajaan Kampa berada ditepi sungai besar yaitu Sungai Kampar. Pemilihan lokasi tersebut dikarenakan sungai merupakan transportasi utama yang digunakan dan tanah subur untuk pertanian masyarakat (Datuok Bagindo dan Datuok Majo Besar, 2021). Berdasarkan pengukuran melalui survey topografi (2018) kompleks Kerajaan Kampa memiliki ketinggian hingga $25 \mathrm{mdpl}$ (meter diatas permuakaan laut), dengan tingkat kelerengan lahan berkisar antara 0 $5 \%$ pada lahan dan kemiringan $0-70 \%$ ditepi sungai Kampar. Kawasan ini memiliki 2 (dua) jenis tanah yaitu: tanah organosol dan gley humus dalam bentuk rawarawa atau tanah basah.

Kondisi hidrologi di wilayah kompleks terdapat jenis potensi air permukaan (sungai), air tanah dalam, air tanah dangkal, dan akuifer produktivitas tinggi. Kondisi seperti ini mampu memberikan dukungan yang baik terhadap ketersediaan air baku untuk kebutuhan air bersih, kegiatan pertanian, dan kegiatan masyarakat lainnya. Pada kawasan terdapat jenis sungai permanen yaitu sungai Kampar dan anak sungai. Debit air sungai sepanjang tahun relatif tetap, namun ada kenaikan pada musim hujan. Pola aliran sungai pada kawasan yaitu dendritik dimana pergerakan sungai besar cukup stabil dan pergerakan anak sungai bermuara pada sungai Kampar. Pertimbangan karakteristik topografi dan ketersediaan air (hidrologi) yang baik menjadi alasan pemilihan lokasi kompleks Kerajaan Kampa pada masanya (Datuok Majo Besar, 2021).

Datuok Majo Besar (2021) mengatakan bahwa Datuok Samad Dirajo pernah menjelaskan bangunan istana adalah bangunan terakhir berdiri dan roboh pada tahun 1950. Sejak saat itu hingga hari ini yang tersisa berupa kepemilikan tanah dengan fungsi yang telah berubah. Perubahan fungsi seperti digunakan sebagai lahan untuk sekolah, rumah dan kebun masyarakat, lapangan sepakbola, pemakaman masyarakat, dan lahan kosong (Latif, 2018).

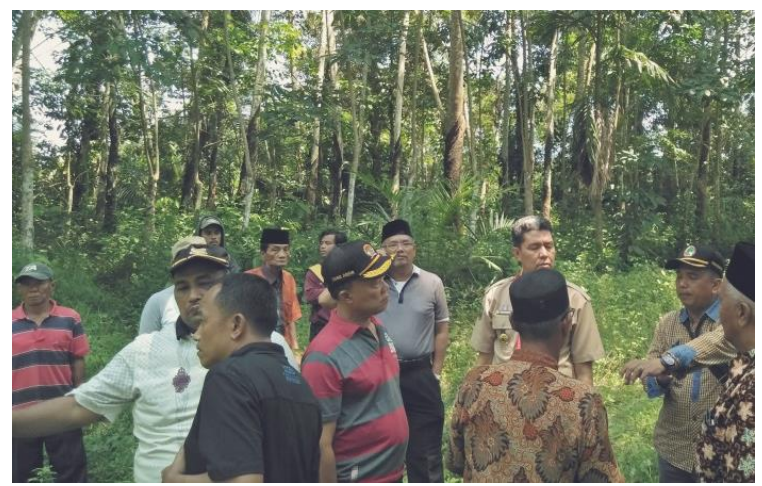

Gambar 3. Observasi Lapangan Kompleks Kerajaan Kampa Bersama Ninik Mamak dan Pemerintah Kabupaten Kampar

\section{Filosofi Penataan Kompleks Kerajaan Kampa}

Datuok Bagindo (2018) menjelaskan sejak dulu seluruh kehidupan bermasyarakat di Kenegerian Kampa diatur dengan nilai-nilai yang menjadi jati diri kepribadian masyarakat Kampar. Jati diri tergambarkan dalam prilaku masyarakat dan pola penataan bangunan. Secara keseluruhan penataan dan fungsi bangunan diatur dengan tujuan tertentu. Datuok Majo Besar (2021) mengatakan jati diri tersebut tertuang dalam makna semboyan "Tali Tigo Sapilin Tigo Tungku Sajorangan".

Datuok Majo Besar (2021) menjelaskan semboyan diwujudkan dalam hubungan masyarakat diatur oleh 3 (tiga) kepemimpinan yang memiliki peran masing-masing yaitu Raja sebagai pemimpin pemerintahan yang sah, Ninik Mamak (Penghulu Adat) sebagai pemimpin persukuan yang berada di Kerajaan Kampa sekaligus membantu raja dalam menjalankan pemerintahan, dan Ulama sebagai pemimpin agama di Kerajaan Kampa mengatur menjalankan kehidupan 
beragama sekaligus sebagai penasehat raja. Tiga pemangku tersebut merupakan peran kunci ini saling menguatkan keberlangsungan Kerajaan Kampa sehingga perlu saling bekerja sama.

Semboyan Tali Tigo Sapilin Tigo Tungku Sajorangan tersebut diekspresikan dalam mengatur kompleks Kerajaan Kampa. Sehingga ada hirarki dalam pengaturan zonasi dan perletakan fungsi didalam kompleks Kerajaan Kampa seperti ada ruang untuk raja menjalankan pemerintahan, ada ruang untuk Ninik Mamak mengatur anak kemenakan (persukuan), dan ada masjid sebagai pusat keagamaan bagi ulama. Tiga (3) bagian ini berada di satu kompleks dengan menampati ruang masing-masing secara independen namun saling berinteraksi dalam musyawarah (Datuok Tumenggung, 2021).

\section{Fungsi-Fungsi Pada Kompleks Kerajaan Kampa}

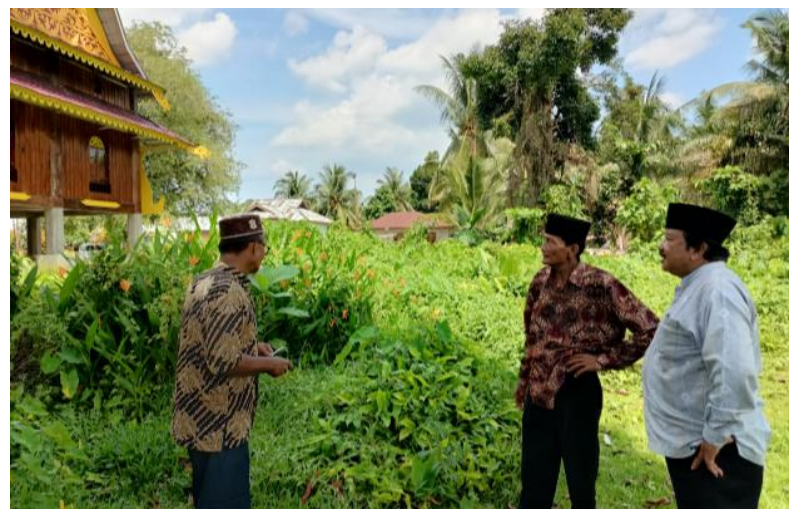

Gambar 4. Peninjauan Fungsi Kompleks Kerajaan Kampa Bersama Datuok Kenegerian Kampa

Berikut bangunan dan fungsinya pada kompleks Kerajaan Kampa (Datuok Majo Besar, 2021) :

1. Istana Raja berfungsi sebagai rumah kediaman raja dan keluarga,

2. Balai Adat berfungsi sebagai ruang pertemuan raja dengan Ninik Mamak (Penghulu Adat) dan menyambut tamu Kerajaan Kampa,

3. Topian Raja berfungsi sebagai area pemandian khusus keluarga kerajaan di tepi sungai Kampar,

4. Dermaga Raja berfungsi sebagai pelabuhan kerajaan sebab transportasi saat itu adalah kapal di sungai Kampar,

5. Pohon Asam Jawa berfungsi penanda halaman raja dan menjadi poros Istana,

6. Rumah Ninik Mamak (Penghulu Adat) sebagai kediaman Ninik Mamak,

7. Pasar Pekan Tua berfungsi wadah perekonomian Kerajaan Kampa, dan

8. Masjid Kubro berfungsi sebagai pusat keagamaan Kerajaan Kampa.

\section{Tata Ruang dan Perletakan Bangunan Pada Kompleks Kerajaan Kampa}

Penataan ruang kompleks Kerajaan Kampa merupakan wujud dari semboyan Tali Tigo Sapilin Tigo Tunggu Sajorangan dimana tersusun secara kompak antara area yang difungsikan untuk aktifitas raja (keluarga raja) baik secara pribadi maupun pemerintah, area untuk aktifitas Ninik Mamak baik untuk pribadi maupun menerima anak kemenakan (persukuan), serta area pusat keagamaan. Tiga hirarki fungsi ini berada diatas tanah kepemilikan Kenegerian Kampa. Masingmasing bangunan untuk tiap aspek berada tidak jauh antara satu sama lain sebab adanya saling berinteraksi (Datuok Majo Besar dan Datuok Datuok Tumenggung, 2021).

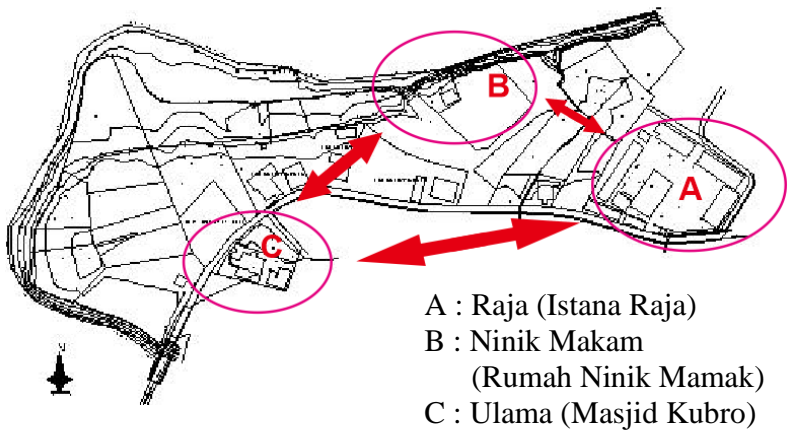

Gambar 5. Pola Penataan Ruang kompleks Kerajaan Kampa

Datuok Bagindo (2018) mengatakan posisi fungsi utama berdekatan tersebut bertujuan untuk memudahkan pergerakan. Struktur tata ruang yang membentuk 3 (tiga) pusat yang memiliki karakter masing-masing. Ketiga poros ini akan diikuti oleh fasilitas pendukung kenegerian dan pemukiman masyarakat disekitarnya.

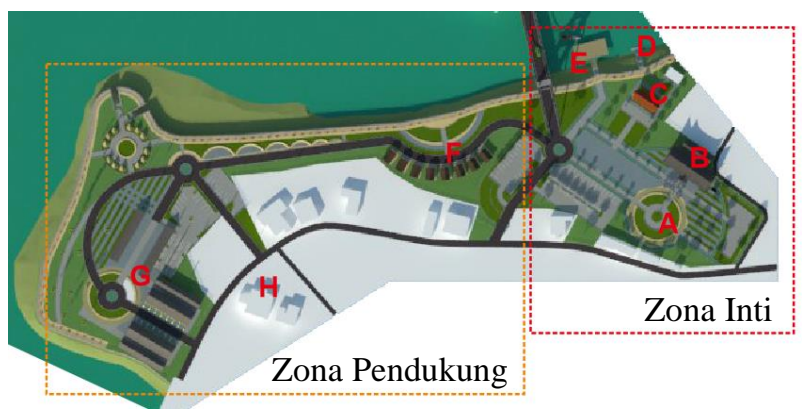
A : Pohon Asam Jawa
$\mathrm{B}$ : Istana raja
C : Balai Adat
D : Topian raja

\begin{abstract}
$\mathrm{E}$ :Dermaga raja F : Rumah Ninik Mamak G : Pasar Pekan Tua $\mathrm{H}$ : Masjid Kubro
\end{abstract}

Gambar 6. Zonasi Kompleks Kerajaan Kampa Secara mikro kompleks ini dibagi atas 2 (dua) zonasi, yaitu zona inti dan zona pendukung (Datuok 
Marajo, 2021). Zonasi ini dibentuk untuk menjadi aturan penggunaan ruang oleh pengguna yaitu keluarga kerajaan, ninik mamak, ulama, dan masyarakat. Akses penggunaan kawasan terbatas pada tujuan tertentu seperti menemui Raja, menemui Ninik Mamak, dan beribadah atau memanfaatkan fungsi pendukung.

Zona inti merupakan zona utama yang bersifat tertutup atau sakral. Zona inti adalah fungsi kerajaan yang meliputi bangunan Istana Raja, Balai Adat, Topian (pemandian Raja), Dermaga Raja. Zona ini adalah kegiatan-kegiatan keluarga raja. Masyarakat tidak dibenarkan untuk memasuki tanpa seijin Dubalang (perangkat keamanan raja). Kegiatan zona inti tergolong formal kerajaan seperti menyambut tamu kerajaan, musyawarah adat dengan Ninik Mamak (Penghulu), dan tamu khusus raja (Datuok Majo Besar, 2021). Zona inti berada di sisi timur kompleks Kerajaan Kampa.

Selanjutnya, zona pendukung tergolong informal namun ada aturan-aturan bagi masyarakat seperti menaati Ulama dan Ninik Mamak. Zona pendukung diletakkan fungsi rumah Ninik Mamak (penghulu), Masjid Kubro, Pasar Pekan Tua, kebun, dan ruang terbuka. Aksesibilitas area ini bersifat umum bagi masyarakat dapat dimasuki secara terbuka. Kegiatan zona ini seperti mengunjungi Ninik Mamak, kegiatan jual beli, dan beribadah di masjid. Zona pendukung ini berada memanjang ke sisi barat kompleks Kerajaan Kampa.

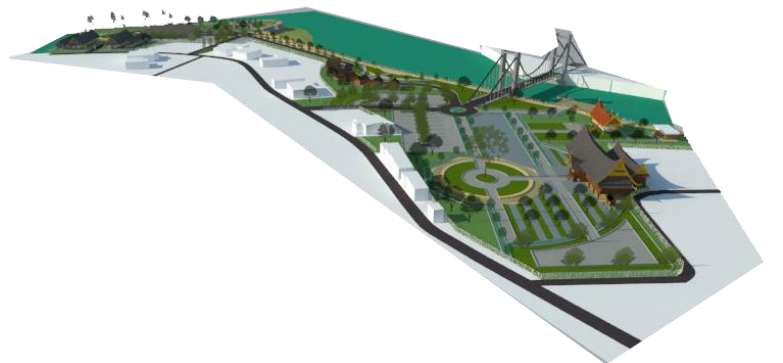

Gambar 7. Areal View Kompleks Kerajaan Kampa

\section{Pola Pergerakan Pada Kompleks Kerajaan Kampa}

Pola pergerakan pada kompleks Kerajaan Kampa dipengaruhi oleh aktifitas penggunaan spasial dan tautan antar fungsi dan zona. Pergerakan yang dikehendaki dilakukan baik didalam internal maupun ekternal kompleks Kerajaan Kampa. Berikut hirarki pola pergerakan pada Kompleks Kerajaan Kampa (Datuok Tumenggung, 2021). :

1. Pergerakan Internal Zona Inti kerajaan Pergerakan internal yang dimaksud adalah pola pergerakan yang dilakukan oleh keluarga kerajaan di zona inti yaitu fungsi kediaman raja. Aktifitas yang diijinkan adalah keluarga kerajaan dalam melaksanakan aktifitas harian seperti Istana, Topian pemandian raja, Dermaga raja, dan menuju Balai Adat jika ada musyawarah.

2. Pergerakan Sub Internal Kompeks

Pergerakan sub internal kompleks yang dimaksud adalah pergerakan antar fungsi didalam keseluruhan kompleks kerajaan seperti tautan pergerakan antara istana raja, masjid, dan rumah Ninik Mamak. Hal ini menunjukkan pola segitiga.

3. Pergerakan Eksternal

Pergerakan ini menggambarkan pergerakan menuju atau keluar dari kompleks Kerajaan Kampa.

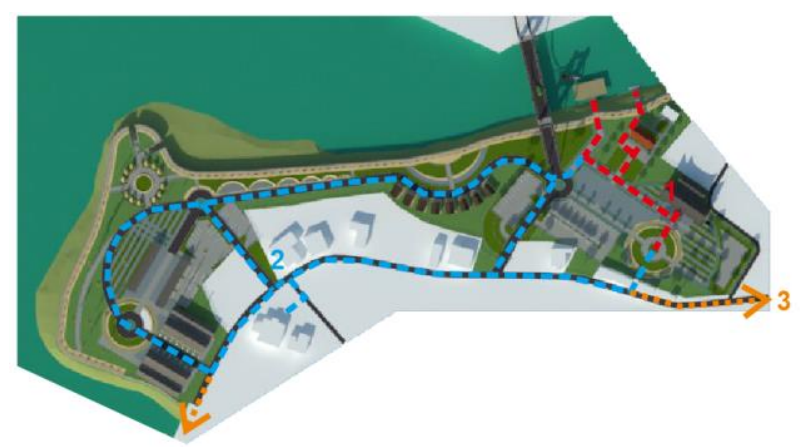

Gambar 8. Pola Pergerakan Kompleks Kerajaan Kampa

\section{Bangunan Istana Kerajaan Kampa}

Istana Kerajaan Kampa dikembalikan semirip mungkin kebentuk asli melalui sumber lukisan yang divalidasi oleh Ninik Mamak. Berikut karakter bangunan Istana Kerajaan Kampa (Datuok Bagindo, Datuok Majo Besar, Datuok Tumenggung, 2021)

1. Posisi letak Istana lurus berhadapan dengan pohon Asam Jawa yang berada di halaman istana,

2. Pada ruang induk istana menggunakan 8 kolom kesamping dan 3 kolom ke belakang sedangkan dapur menggunakan 5 kolom kesamping dan 2 kolom kebelakang dengan jarak antar kolom adalah 4 meter,

3. Bentuk kolom bangunan adalah segi 8 berdasarkan filosofi penjuru mata angin,

4. Bangunan berbentuk lontiok (lentik) atap bertingkat yang sedikit laya / landai pada ruang induk, dan satu tingkat pada dapur,

5. Adanya ukiran seperti Kelok Paku, Pucuk Rebung, Akar Paku, Gasing, dan lain sebagainya,

6. Bangunan berbentuk panggung dengan tinggi lantai dari tanah adalah $\pm 2,5$ meter (acuan setinggi orang dewasa ditambah \pm 2 jengkal),

7. Tinggi dinding bangunan adalah $\pm 2,5$ meter lebih (tinggi orang dewasa ditambah \pm 1 hasta), tinggi atap lebih dari badan agar terlihat megah.

8. Pondasi menggunakan pondasi umpak, dan 
9. Ruang terbagi atas selasar, kamar raja, kamar anak, bodi (penghubung dapur), dan area belakang (dapur).

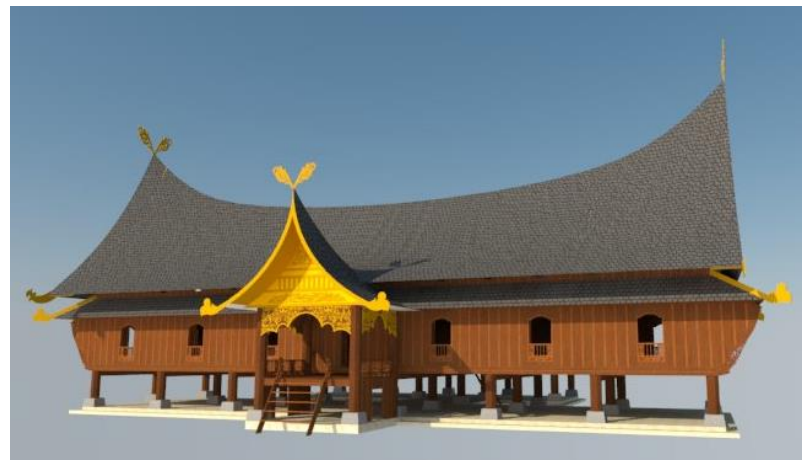

Gambar 9. Model Istana Kerajaan Kampa

\section{KESIMPULAN}

Upaya restorasi kompleks Kerajaan Kampa harus selalu diupayakan dengan bekerja sama berbagai pihak seperti peneliti, Ninik Mamak, dan Pemerintah Kabupaten Kampar. Hal ini tentu akan memberikan benang merah masa lalu, masa sekarang, dan masa akan datang (Suhermi Ketua tim Percepatan Restorasi Kerajaan kampa Pemerintah Kabupaten Kampa, 2021). Selanjutnya Datuok Tumenggung (2021) menjelaskan selain menjaga sejarah tentu kedepannya restorasi ini dapat dijadikan sebagai cagar budaya yang menggambarkan akar budaya dan arsitektur melayu khususnya Kenegerian Kampa di Kabupaten Kampar. Lebih jauh lagi kompleks Kerajaan Kampa ini dapat dijadikan wisata arsitektur dan budaya, sehingga dapat meningkatkan ekonomi masyarakat sekitar dan pendapatan daerah. Upaya restorasi ini bersumberkan pada wawancara Datuok / Ninik Mamak Kenegerian Kampa.

Kompleks Kerajaan Kampa dilakukan dengan hati-hati melalui restorasi dengan dasar dan sumber sejarah dengan melibatkan sumber-sumber utama seperti pelaku yaitu Datuok/Ninik Mamak dan sumber lain yang divalidasi oleh Datuok/Ninik Mamak. Kompleks Kerajaan Kampa berlokasi di tepian sungai Kampar karena pertimbangan transportasi dan kesuburan tanah untuk pertanian (Datuok Majo Besar, 2021). Sejak dulu budaya tinggi dengan dasar semboyan Tali Tigo Sapilin Tigo Tungku Sajorangan menjadi filosofi berprilaku. Semboyan ini menjadi dasar penentuan penataan ruang dengan meletakkan fungsi bangunan pada tempatnya. Hal ini akan memperlihatkan kekuatan yang saling menguatkan antara raja selaku pemimpin pemerintah, Ninik Mamak selaku pemimpin kaum (adat), dan Ulama selaku pemimpin agama. Tiga aspek tersebut bekerja sama saling membantu dan memberikan nasehat tanpa mengenyampingkan peran satu sama lainnya.
Pada penataan ruang 3 aspek tersebut diletakkan pada posisi masing-masing dengan jarak tidak jauh sehingga dapat merespon kondisi tertentu secara cepat. Pada kompleks Kerajaan Kampa didapatkan pembagian zona inti yang difungsikan sebagai fungsi kerajaan dan zona pendukung yang difungsikan sebagai kediaman Ninik Mamak, masjid, dan pasar. Pergerakan ketiganya sangat fleksibel sebab adanya jarak dan jalur sirkulasi masing-masing. Datuok Bagindo (2018) mengatakan istana Kerajaan Kampa identik dengan arsitektur melayu yang ditandai dengan atap lontiok (Lentik) bertingkat, adanya selembayung di ujung atap dan bangunan berpanggung.

\section{REFERENSI}

Attoe, Wayne. (1978) Architecture and Critical Imagination, John Wiley \& Sons

Bogdan, R.C., \& Biklen, S.K.B. (1998) Qualitative Reseach for Education to Theory and Methods. Allyn and Bacon, Inc

Charter, Burra. (1992) Australian's Methodology for Conserving Cultural Heritage

Datuok Majo Besar (2021) Wawancara Datuok Majo Bosau (Besar) Kenegerian Kampa oleh Muhammad Arief Al Husaini. https://youtu.be/wh3pfLoSLDM

Datuok Bagindo, Datuok Tumenggung, Datuok Marajo dan Datuok Majo Besar ( 2021) wawancara tentang sejarah kerajaan Kampa

Datuok Bagindo (2018) wawancara dan suvei bersama Datuok fungsi kompleks kerajaan Kampa

Feilden, Sir Bernard. (2009) A Monument to Building Conservation, Journal of Architectural Conservation $15 . \quad$ DOI 10.1080/13556207.2009.10785036.

Groat, L.N. and Wang, D. (2002) Architectural Research Methods, J. Wiley Inc.

Hasyim, Latif. (2018) Sejarah Singkat Negeri Kampar dan Berdirinya Kerajaan Kampa-Riau, Museum AMM Kampar

Latif Datuok Bagindo, Abdul (2000) Lukisan Istana Kerajaan Kampa

Latif Hasyim Dt. Bagindo, Abdul (2018) Sejarah Singkat Negeri Kampar dan Berdirinya Kerajaan Kampa - Riau. disampaikan pada acara penobatan kembali sultan ke - 14

Orbasli, Aylin. (2000) Tourists in Historic Towns-Urban Conservation and Heritage Menegement, $E \& F N$ Spoon

Ref.UNESCO.PP. 36/2005

Undang Undang RI no 11 Tahun 2010 tentang cagar budaya.

Wasino dan Hartatik, Endah Sri. (2018) Metode Penelitian Sejarah: dari Riset Hingga Penulisan, Magnum Pustaka Utama 